\title{
Turismo receptivo en el Paraguay: una reseña de su aporte a la economía durante el periodo 2003-2017
}

\section{Receptive tourism in Paraguay: a review of their contribution to the economy during the period $2003-2017$}

\author{
Erick Adalberto Schmidt (SCHMIDT, E. A.) ${ }^{*}$; \\ Antonella Cabral López (CABRAL LÓPEZ, M. A.) ${ }^{* *}$
}

RESUMEN - Este material tiene como objetivo presentar los efectos generados por el ingreso de turistas al Paraguay, específicamente en materia económica. Para lograr el propósito trazado con este trabajo, se diseñó una investigación de nivel exploratorio y descriptivo, de tipo bibliográfico - documental, en la que se recurre entre otras herramientas al cálculo de índices sugeridos por distintos organismos internacionales. Este país posee diversos atractivos turísticos y económicos que atraen a los visitantes, aunque la información disponible es muy limitada. Esto constituye una dificultad para los trabajos de investigación a ser desarrollados. Entre los resultados más importantes se encuentran la relevancia del turismo como industria de exportación, la cual se ha expandido notoriamente durante el periodo que abarca este estudio, y su rol para la generación de ingresos de divisas al país por medio de la llegada de turistas, principalmente de los países limítrofes.

Palabras clave: Turismo; Paraguay; Indicadores económicos del turismo; Turismo receptivo.

ABSTRACT - This paper has the purpose of presenting the effects generated by the incoming of tourists to Paraguay, specifically in economic matters. To achieve the purpose outlined in this paper, an exploratory and descriptive level research was designed. In addition, it has been considered a bibliographic - documentary research. Several tools was used, especially suggested indexes by international organizations. This country has several tourist and economic attractions which attracts visitors but despite the information about the activity is limitated. That is a difficulty for the researchers and their works. Among the most outstanding results are the relevance of tourism as an export industry and its importance for the generation of international currency income through the tourists, especially from bordering countries.

Key words: Tourism; Paraguay; Economic indicators of tourism; Receptive tourism.

\footnotetext{
* Economista por la Universidad Nacional de Asunción. Actividad Profesional: Asesor de empresas. Datos de contacto: Av. Carlos A. López 2069, Asunción, Paraguay. E-mail: erick-0601 @ hotmail.com

** Economista por la Universidad Nacional de Asunción, Magíster en Relaciones Internacionales por la Universidad Nacional de La Plata (Argentina). Actividad profesional/Académica: Investigadora de la Facultad de Ciencias Económicas, Universidad Nacional de Asunción. Datos de contacto: José E. Rodó 1027, Asunción, Paraguay. E-mail: antocabral@gmail.com
} 


\section{INTRODUCCIÓN}

Si bien el concepto de turismo es complejo, la Organización Mundial de Turismo (OMT, 2017, s.f.) lo expresa con estos términos:

\footnotetext{
Es un fenómeno social, cultural y económico relacionado con el movimiento de las personas a lugares que se encuentran fuera de su lugar de residencia habitual por motivos personales o de negocios. Estas personas se denominan visitantes, que pueden ser turistas o excursionistas; residentes o no residentes y el turismo tiene que ver con sus actividades, de las cuales algunas implican un gasto turístico.
}

Existe además un sinfín de definiciones esbozadas por diversos autores. Ante la imposibilidad de realizar una revisión exhaustiva de las mismas, sólo se mencionará que la constante en las mismas es la referencia a que los turistas son personas con residencia en otro lugar al considerado y que éstos no realizan ninguna actividad remunerada durante su viaje.

El turismo puede ser una actividad interior, nacional o internacional, dependiendo de donde se realiza. Cada una de las mismas puede tener una dimensión emisora y otra receptora, dependiendo del sentido del desplazamiento (OMT, 2017, s.f.).

Los turistas y los habitantes de los destinos turísticos tienen entre sí un intercambio, el que se ve influenciado por diversos factores. Este intercambio puede ser un aliciente en términos culturales, de identidad y financieros y hacer del destino turístico una plataforma de intercambio (DE LIMA MORAIS; MARQUES ACIOLY, 2018).

Este material tiene como objetivo general presentar una reseña sobre el aporte del turismo receptivo a la economía del Paraguay durante el periodo 2003-2017. Para ello, se parte desde un enfoque vinculado al comercio internacional. Por esta razón, es menester señalar que el comercio internacional puede ser entendido como el proceso por el que países importan y exportan bienes, servicios y capital financiero (SAMUELSON; NORDHAUS, 2006). A través de los años, las teorías existentes en la materia estuvieron centradas fundamentalmente en analizar los flujos de bienes entre países. Sin embargo, en las últimas décadas la relevancia del sector servicios para el intercambio comercial internacional ha sido reconocida. 
En el sector servicios, el turismo puede ser concebido como una actividad exportadora, en la que en lugar de que exista un desplazamiento de productos, es el cliente (o turista) quien llega hasta el vendedor (DE RUS, G.; LEÓN, C., 1997). Siguiendo con este razonamiento, y teniendo en cuenta las características propias del turista, que serán detalladas más adelante, es posible aseverar que la persona que se traslada debe consecuentemente, tener dinero para la subsistencia durante su estadía, dejando directa o indirectamente un ingreso de flujo de efectivo para algún sector del país o región.

Es preciso mencionar que la economía siente los efectos del turismo a través de la renta generada, la creación de empleo, el ingreso de divisas que ayudan a equilibrar la balanza de pagos, el aumento de los ingresos públicos y el fomento de la actividad empresarial. Estas variables son algunas de las que permiten apreciar la importancia que puede cobrar la actividad turística para la generación del Valor Agregado Bruto en la región receptora.

Estos efectos se han notado a nivel internacional, donde se apreció una evolución positiva de la actividad turística en el tiempo, la que se ha mostrado cíclica, con rápidas recuperaciones luego de periodos de crisis. Esto permite inferir que existe una estrecha vinculación entre la actividad turística y el crecimiento económico (SANCHO, 2008).

Sin embargo, la actividad turística no representa únicamente un factor positivo. Algunos de los posibles efectos negativos se vinculan con la utilización masiva de infraestructura, el desgaste del medio físico, un incremento en los gastos para el mantenimiento de los bienes, el desarraigo y la pérdida de tradiciones, entre otras. De Rus y León (1997) explican que por esta razón, debe efectuarse un análisis costobeneficio, para verificar que sea una actividad socialmente deseable.

Con miras a contribuir con este análisis, se considera el caso paraguayo. Este país ha sido catalogado tradicionalmente como de turismo comercial. Ello significa que el ingreso de personas se realiza con el fin de efectuar compras en Paraguay y posteriormente los turistas retornan a sus países. Sin embargo, esta situación ha empezado a cambiar con el tiempo. Esto se debió a que la oferta turística paraguaya fue expandiéndose, particularmente en lo que concierne al entorno natural y puesta en valor de sitios históricos. 
Como evidencia de este cambio, puede reseñarse la creación de la Secretaría Nacional de Turismo (SENATUR), la cual fue establecida por medio de la LEY N$^{\circ}$ 1.388/98. Esta normativa especificaba en su Art. $2^{\circ}$, que entre las funciones de esta secretaría de Estado se encontraba la promoción del turismo interno e internacional y la difusión del turismo cultural y ecológico, entre otras.

Partiendo de estas premisas fue elaborado el "Plan Maestro de Desarrollo Sostenible del Sector Turístico de Paraguay" (2012 - 2018). Este documento expresaba la visión turística del país, la que se vinculaba con elementos como ser: la organización de eventos y convenciones, la promoción de su naturaleza y la difusión de la cultura autóctona, enfatizando en la sustentabilidad y el valor del turismo como uno de los principales sectores productivos del país (SENATUR, 2012).

\section{METODOLOGÍA}

Este material fue elaborado a partir de un diseño metodológico descriptivo, de tipo documental/bibliográfico. La información procesada provenía fundamentalmente de fuentes vinculadas a la SENATUR, Banco Central del Paraguay (BCP), Dirección General de Migraciones (DGM), Banco Mundial (BM), Organización Mundial del Turismo (OMT), Comisión Económica para América Latina y el Caribe (CEPAL), por citar algunas. El método empleado fue el analítico y sintético.

Los índices calculados se basaron en una propuesta metodológica de la CEPAL y son detallados a continuación:

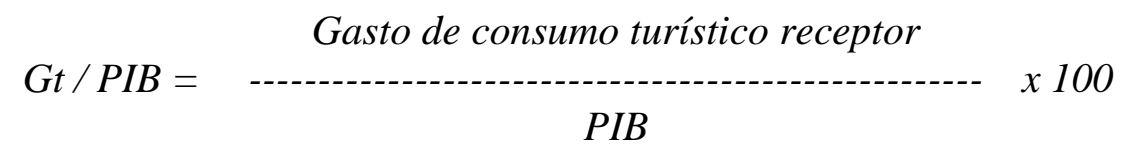

El gasto del turismo con respecto a bienes y servicios se calcula con la siguiente ecuación:

Gasto de turismo receptivo

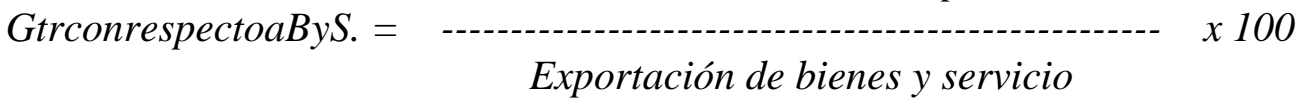


Debido a la carencia de ciertos datos específicos sobre este sector, no fue posible el cálculo de otro tipo de modelos más complejos existentes en la literatura, por lo que se avizora la importancia de fortalecer la disponibilidad de estadísticas en la materia.

\section{FUNDAMENTACIÓN TEÓRICA}

La OMT (2017, p. 3) afirma que la importancia del turismo puede apreciarse en distintos aspectos. Entre los mismos, señala que uno de cada 10 empleos en el mercado mundial se relaciona con esta actividad, la cual representa el 10\% del PIB Global y el $30 \%$ de las exportaciones de servicio. Además tiene un rol clave para la preservación cultural, el mantenimiento de la paz y la seguridad y la protección del medio ambiente.

De Rus y León (1997, p. 72) mencionan la importancia de definir al turismo como actividad económica. Para ello, recurren a lo esbozado por Jafari (1977), quien afirmó "el turismo es el estudio del hombre lejos de su hábitat, de la industria que satisface sus necesidades, y de los impactos del hombre y la industria sobre el entorno socio-cultural de los residentes, sobre su economía y el medio ambiente". Estos autores precisan que a pesar de poseer un proceso de producción de servicios similar a otros, el turismo tiene características que lo diferencian de otras actividades (FIGURA 1). 
FIGURA 1 - CARACTERÍSTICAS DIFERENCIADORAS DEL TURISMO

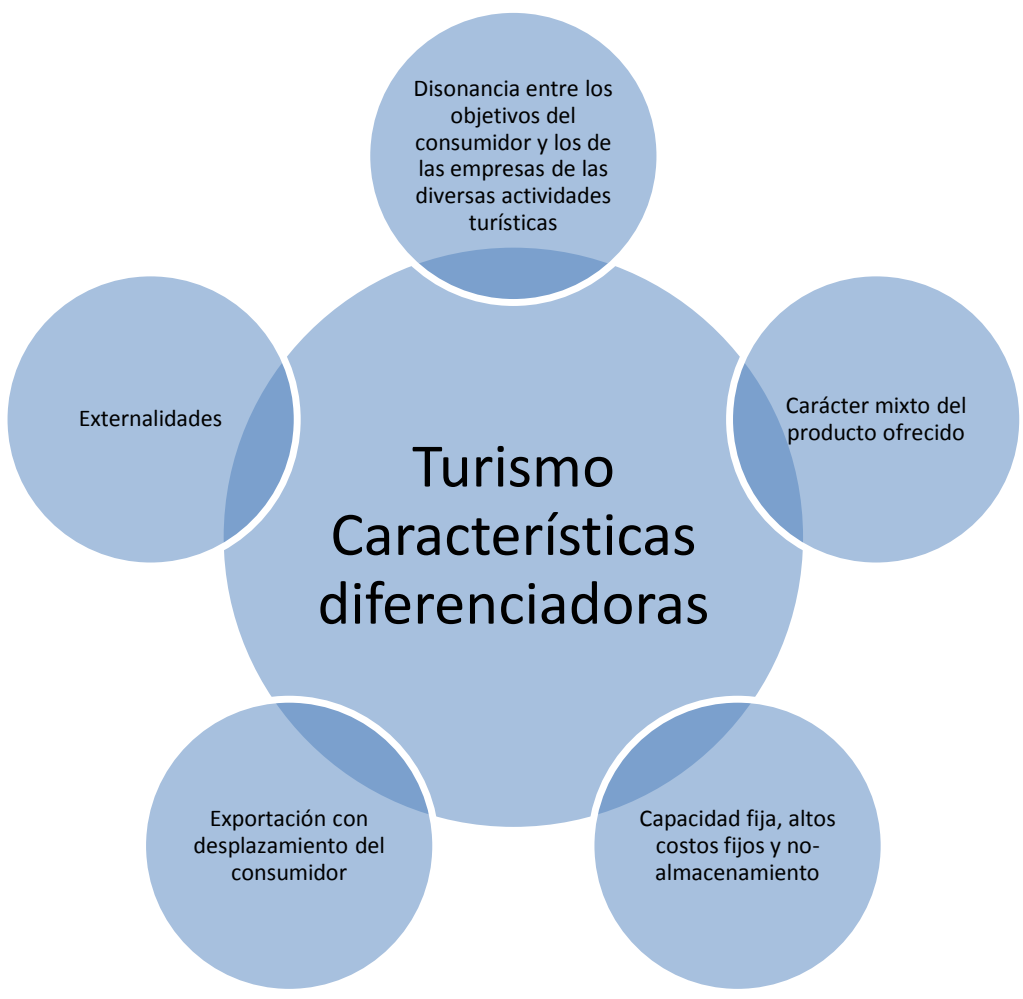

FUENTE: Elaboración propia en base a De Rus y León (1997, p. 72).

Entre las características reseñadas, la relacionada con la disonancia entre los objetivos de cada actor se vincula a que mientras que el turista busca una experiencia integral, el oferente se centra sólo en el producto que le compete, lo que provoca problemas de información y coordinación. Por su parte, el carácter mixto del producto obedece a que los servicios privados se amalgaman con la infraestructura pública y los recursos naturales, mientras que la capacidad fija, altos costes fijos y noalmacenamiento repercuten generando bajos costos variables.

La exportación con desplazamiento del consumidor, es una peculiaridad que hace que pueda asemejarse a otro tipo de exportaciones y con ello posibilita que la teoría relacionada al comercio exterior ofrezca ciertas herramientas analíticas para esta actividad. Finalmente, las externalidades tienen que ver con aspectos derivados de la actividad turística, como ser la afluencia en ciertos espacios (como ejemplo de externalidad negativa) y la creación de infraestructura (como ejemplo de externalidad positiva). 


\subsection{EL MERCADO TURÍSTICO}

El mercado turístico permite que interactúen la oferta y la demanda turística. Sin embargo, por las características reseñadas, es oportuno señalar que involucra una serie de productos e industrias. Debido a la amplitud de los mismos y de manera a que los mismos sean visualizados de forma sencilla, en el Cuadro 1 se los puede observar de forma agrupada. La amplitud de los productos e industrias señalados precedentemente, son una muestra del gran alcance del mercado turístico.

\section{CUADRO 1 - PRODUCTOS E INDUSTRIAS TURÍSTICAS}

\begin{tabular}{|c|c|}
\hline Productos & Industrias \\
\hline 1. Servicios de alojamiento para visitantes & 1. Alojamiento para visitantes \\
\hline 2. Servicios de provisión de alimentos y bebidas & 2. Actividades de provisión de alimentos y bebidas \\
\hline 3. Servicios de transporte de pasajeros por ferrocarril & 3. Transporte de pasajeros por ferrocarril \\
\hline 4. Servicios de transporte de pasajeros por carretera & 4. Transporte de pasajeros por carretera \\
\hline 5. Servicios de transporte de pasajeros por agua & 5. Transporte de pasajeros por agua \\
\hline 6. Servicios de transporte aéreo de pasajeros & 6. Transporte aéreo de pasajeros \\
\hline 7. Servicios de alquiler de equipos de transporte & 7. Alquiler de equipos de transporte \\
\hline 8. Agencias de viajes y otros servicios de reservas & $\begin{array}{l}\text { 8. Actividades de agencias de viajes y de otros } \\
\text { servicios de reservas }\end{array}$ \\
\hline 9. Servicios culturales & 9. Actividades culturales \\
\hline 10. Servicios deportivos y recreativos & 10. Actividades deportivas y recreativas \\
\hline $\begin{array}{l}\text { 11. Bienes característicos del turismo, específicos de } \\
\text { cada país }\end{array}$ & $\begin{array}{l}\text { 11. Comercio al por menor de bienes característicos del } \\
\text { turismo, específicos de cada país }\end{array}$ \\
\hline
\end{tabular}
FUENTE: Organización Mundial del Turismo (2017, s.f.).

La importancia y complejidad del tema que han sido detalladas en líneas anteriores llevaron a la realización de múltiples estudios a nivel internacional tanto de la demanda como de la oferta. Existen diversos e interesantes estudios en torno a la oferta y demanda en forma independiente o integrada (GRUPO DE INVESTIGACIÓN EN ECONOMÍA REGIONAL, 2017).

Por el lado de la demanda, Esteban Talaya y Reinares Lara (1996) efectuaron para el caso español, el agrupamiento de los estudios de la demanda en 4 conglomerados: estudios de demanda turística global, estudios de demanda turística por 
zonas geográficas emisoras y receptoras, estudios de la demanda de servicios/productos turísticos, estudios de previsión de la demanda turística; los cuales pueden resultar válidos para lo producido en distintas latitudes. En lo concerniente a la oferta, se apreciaron distintos enfoques, desde aquellos que parten de una descripción de la misma (MESA LONDOÑO et al. 2010) hasta aquellos que amalgaman sofisticados métodos de análisis (FERREIRA LOPES; VELOSO DA SILVA, 2011).

La literatura existente es basta, como se observó y motiva a desarrollar distintos estudios. Sin embargo, pudo notarse que para el caso de Paraguay, los mismos deben hacer frente a dos aspectos cruciales para el estudio del sector: la necesidad de contar con datos específicos de los diversos productos e industrias, material del que por lo general se carece para el caso paraguayo y la importancia de confeccionar cuentas satélite de turismo ${ }^{1}$. Por ello en este trabajó se optó por el trabajo con diversos índices, tal cómo se señaló en el apartado correspondiente a la metodología.

\subsection{TURISMO RECEPTIVO}

El turismo receptivo, como otras actividades, repercute en el entorno en el que se desarrolla. Sin embargo, estos efectos pueden ser positivos o negativos y ser clasificados en tres dimensiones principales, según Quintero Santos (2004): impacto sociocultural, impacto medioambiental e impacto económico.

Rodrigues Marins, Feder Mayer y Fratucci (2015) explican que estos impactos se materializan en contradicciones. Esto se debe a que si bien la actividad turística es multidimensional y si bien reporta beneficios sociales, económicos y culturales para los agentes y las localidades, también pueden generar tensiones, crear dependencia económica y degradar el ambiente. Debido a lo expuesto, es posible notar que el turismo transforma espacios y esto tiene una repercusión en el territorio.

En materia económica, se destaca el movimiento de divisas que se genera debido a la actividad turística receptiva, lo cual puede favorecer a la balanza de pagos del país. En sentido contrario, esto puede ocurrir con el turismo emisor; el cual significa una fuga

\footnotetext{
${ }^{1}$ Es un instrumento desarrollado por las Naciones Unidas para medir sectores de la economía que no se consideran como industrias en el sistema de cuentas nacionales. En este caso, el turismo amalgama sectores como el transporte, hospedaje, alimentación, entretenimiento y agencias de viaje, entre otros. Su implementación brindará la posibilidad de comparar distintas economías (ORGANIZACIÓN MUNDIAL DE TURISMO, 2017, s. f.).
} 
de divisas (QUINTERO SANTOS, 2004). Así también, Altamira y Muñoz (2007) explican que se registra una expansión del empleo en los sectores vinculados. El efecto en el empleo podría ser de tres tipos de acuerdo a la OMT (2017, s. f.):

- Directo: el empleo directamente generado por la actividad turística, como los empleados de un hotel. En muchos casos, el empleo directo generado puede ser muy escaso (en zonas de turismo residencial, por ejemplo).

- Indirecto: empleo generado en otros sectores cuya existencia no depende, en general, del turismo (taxistas, teatros, etc.).

- Inducido: empleo generado por el aumento en la demanda de bienes y servicios.

La inversión en turismo repercute en toda la economía. Hernández Martín (2004) explica que debido a los impactos directos e indirectos de la misma, se redistribuye en distintos sectores en forma de salarios, comisiones, beneficios y utilidades, generando un efecto en la cadena. Afirma también que si estas inversiones son desarrolladas planificadamente, podría inclusive irse intensificando hacia aquellos sectores con menor impacto.

Contrariamente, el turismo también tiene efectos no deseables en la economía. Entre ellos puede detallarse la concentración de capitales en determinados sectores, lo que deja muy expuesto al país frente a crisis de esta actividad. Como ejemplo puede citarse como los factores climáticos, terrorismo y/o enfermedades podría mermar el turismo, y con ello afectar a todas las inversiones del sector. Dependiendo de la concentración de las inversiones, el impacto económico del turismo en la renta y el empleo será mayor o menor. Otras consecuencias serían el aumento de la inflación y de las importaciones, como resultado de los nuevos hábitos de consumo. Cada uno de estos factores debe ser ponderado de forma particular y conforme al caso que se esté analizando.

A la luz del caso paraguayo, es posible apreciar que las inversiones en el sector turismo han ido creciendo en los últimos años aunque las mismas sean de difícil identificación en las estadísticas disponibles y cuantía moderada (BANCO CENTRAL DEL PARAGUAY, 2018). Esto hace que las crisis en el sector no sean tan notorias como las acontecidas en otros sectores con mayor visibilidad, aunque esto no significa que su alcance sea menor. 
Las repercusiones de esta actividad conducen a plantear un aspecto clave: la sustentabilidad. Este vocablo si bien ha sido utilizado en particular para el aspecto económico, abarca todas las dimensiones de las relaciones humanas y su interacción con el entorno (RODRIGUES MARINS et al. 2015). Esta idea motiva una fuerte reflexión acerca de si el turismo además del aspecto económico, el cual es reseñado en esta investigación, tiene una repercusión positiva para el Paraguay, su nación y territorio. Debido a que este análisis escapa del alcance del trabajo, se lo plantea como una posible línea a seguir en futuras investigaciones.

Por ello, en el apartado siguiente se presentarán datos referentes a la situación del turismo receptivo en Paraguay.

\section{RESULTADOS}

De manera a tener un primer panorama de la situación del turismo receptivo en Paraguay, se presentan los datos referentes a ingreso de turistas y excursionistas ${ }^{2}$ en la Tabla 1. A partir de la misma, se distingue que tanto el número de turistas como excursionistas ha crecido con el paso del tiempo, aunque el número de turistas ha crecido más robustamente. Esto se aprecia en que en promedio, en el periodo comprendido del 2003 al 2017, se observó un crecimiento del 14,39\% de turistas.

Cabe destacar que más allá del sostenido, aunque variable crecimiento, el año 2015 se observó un salto cuantitativo que permitió un aumento del 87\% respecto al año anterior. Esto lo que ubicó a Paraguay como primer país a nivel mundial en lo que respecta al crecimiento del número de turistas. A partir de este salto, se dio un desplazamiento en la cantidad de turistas que recibió el país. Esto podría encontrar una explicación en diversos factores: la visita del Papa Francisco, que expandió notoriamente la cantidad de personas que ingresaron en 2015; la mejor institucionalidad estatal que respaldó la actividad turística; una mayor oferta de parte del sector privado; las condiciones económicas de los países vecinos y la coyuntura económica del mismo país.

\footnotetext{
${ }^{2}$ La diferencia entre estas figuras, radica en la cantidad de noches en las que cada uno de ellos pernocta en el destino turístico considerado. Además del nivel de gasto, el cual asciende en promedio a USD 351 para los turistas y tan sólo a USD 20 para los excursionistas (SENATUR, 2016).
} 
TABLA 1 - INGRESO DE TURISTAS Y EXCURSIONISTAS AL PARAGUAY. PERIODO $2003-2017$

\begin{tabular}{|c|c|c|c|c|c|}
\hline Año & $\begin{array}{c}\mathbf{N}^{\circ} \mathbf{d e} \\
\text { Turistas }\end{array}$ & $\begin{array}{c}\text { \% Variación } \\
\text { Interanual }\end{array}$ & $\mathbf{N}^{\circ}$ Excursionistas & $\begin{array}{c}\text { \% Variación } \\
\text { Interanual }\end{array}$ & $\begin{array}{c}\text { Total visitantes } \\
\mathbf{y} \\
\text { excursionistas }\end{array}$ \\
\hline 2003 & 268.175 & $7,09 \%$ & 2.591 .076 & $-12,0 \%$ & 2.859 .251 \\
\hline 2004 & 309.287 & $15,33 \%$ & 2.280 .147 & $-12,0 \%$ & 2.589 .434 \\
\hline 2005 & 340.845 & $10,20 \%$ & 2.394 .154 & $5,0 \%$ & 2.734 .999 \\
\hline 2006 & 388.465 & $13,97 \%$ & 2.442 .037 & $2,0 \%$ & 2.830 .502 \\
\hline 2007 & 415.702 & $7,01 \%$ & 2.588 .559 & $6,0 \%$ & 3.004 .261 \\
\hline 2008 & 428.215 & $3,01 \%$ & 2.690 .162 & $3,9 \%$ & 3.118 .377 \\
\hline 2009 & 439.246 & $2,58 \%$ & 2.528 .752 & $-6,0 \%$ & 2.967 .998 \\
\hline 2010 & 465.264 & $5,92 \%$ & 2.705 .765 & $7,0 \%$ & 3.171 .029 \\
\hline 2011 & 523.740 & $12,57 \%$ & 2.841 .053 & $5,0 \%$ & 3.364 .793 \\
\hline 2012 & 579.305 & $10,61 \%$ & 3.058 .767 & $7,7 \%$ & 3.638 .072 \\
\hline 2013 & 609.901 & $5,28 \%$ & 2.929 .439 & $-4,2 \%$ & 3.539 .340 \\
\hline 2014 & 648.962 & $6,40 \%$ & 3.017 .319 & $3,0 \%$ & 3.666 .281 \\
\hline 2015 & 1.214 .613 & $87,16 \%$ & 2.800 .000 & $7,2 \%$ & 4.014 .613 \\
\hline 2016 & 1.308 .198 & $7,70 \%$ & 3.009 .777 & $7,5 \%$ & 4.317 .975 \\
\hline 2017 & 1.583 .937 & $21,08 \%$ & 3.160 .266 & $5 \%$ & 4.744 .203 \\
\hline
\end{tabular}

FUENTE: Elaboración propia a partir de datos proporcionados por SENATUR $(2016,2018)$.

El Gráfico 1 permite apreciar la evolución de visitantes que ha registrado Paraguay. La misma mantiene una tendencia positiva pese a los leves descensos observados en los años 2004, 2009 y 2013. Cabe señalar que el número de turistas ha crecido más robustamente que el número de excursionistas, especialmente entre los años 2013-2018, lo que permite reafirmar que existen condiciones que facilitan que los visitantes pernocten en el país.

GRÁFICO 1 - EVOLUCIÓN DEL TURISMO RECEPTIVO EN PARAGUAY. PERIODO 2003 - 2017

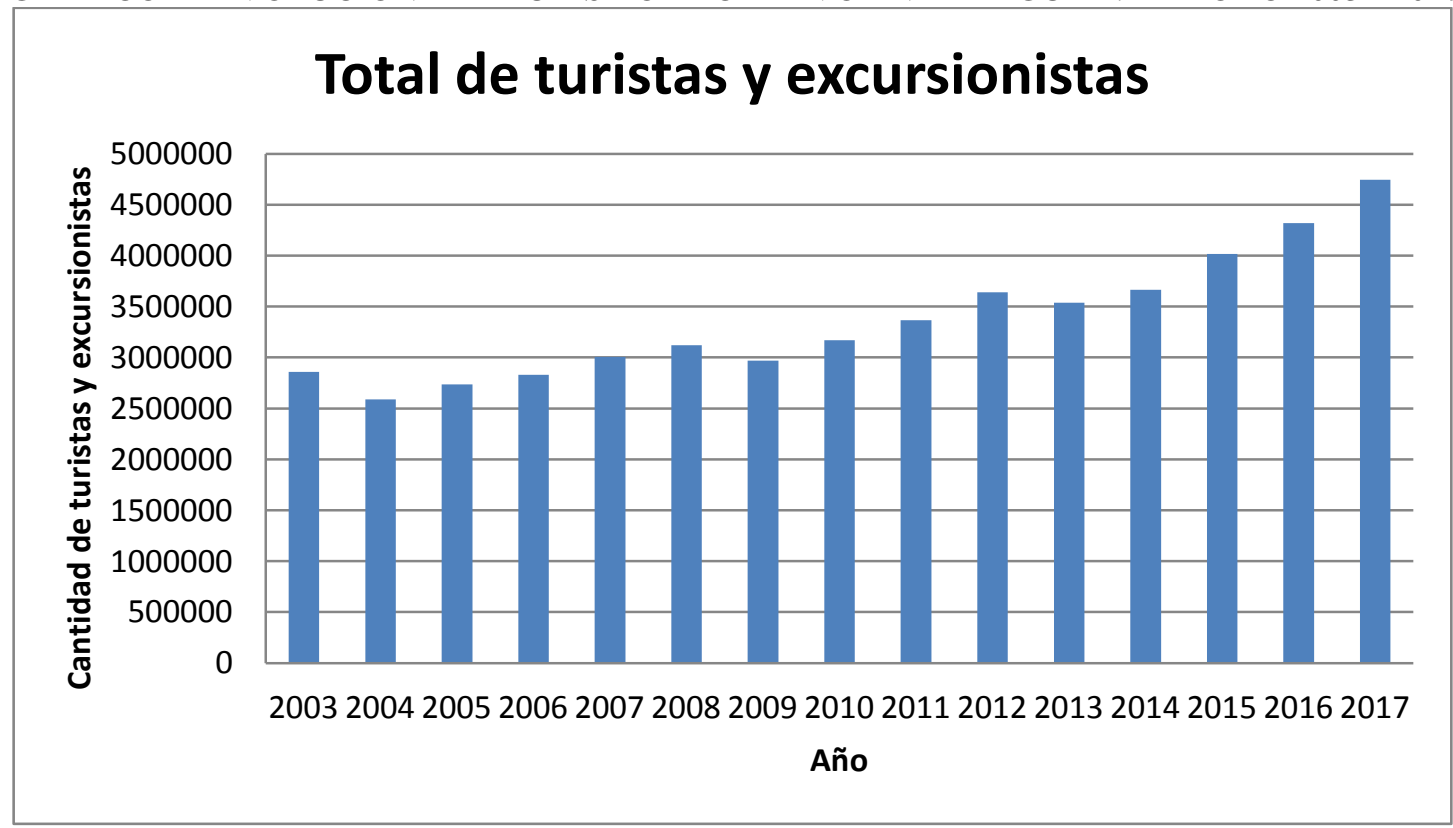

FUENTE: Elaboración propia datos proporcionados de la SENATUR $(2016,2018)$. 
La estacionalidad es una de las características evidenciadas en la actividad turística internacional. Por esta razón, se presenta en el Gráfico 2 la distribución del turismo por meses para el periodo $2006-2013^{3}$. La misma permite apreciar que existe cierta convergencia en cuanto a las distribuciones mensuales, además de la mayor afluencia de visitantes que fue señalada anteriormente. Los meses con mayor afluencia registrada son diciembre, julio, agosto y noviembre, lo que se repite a lo largo del tiempo.

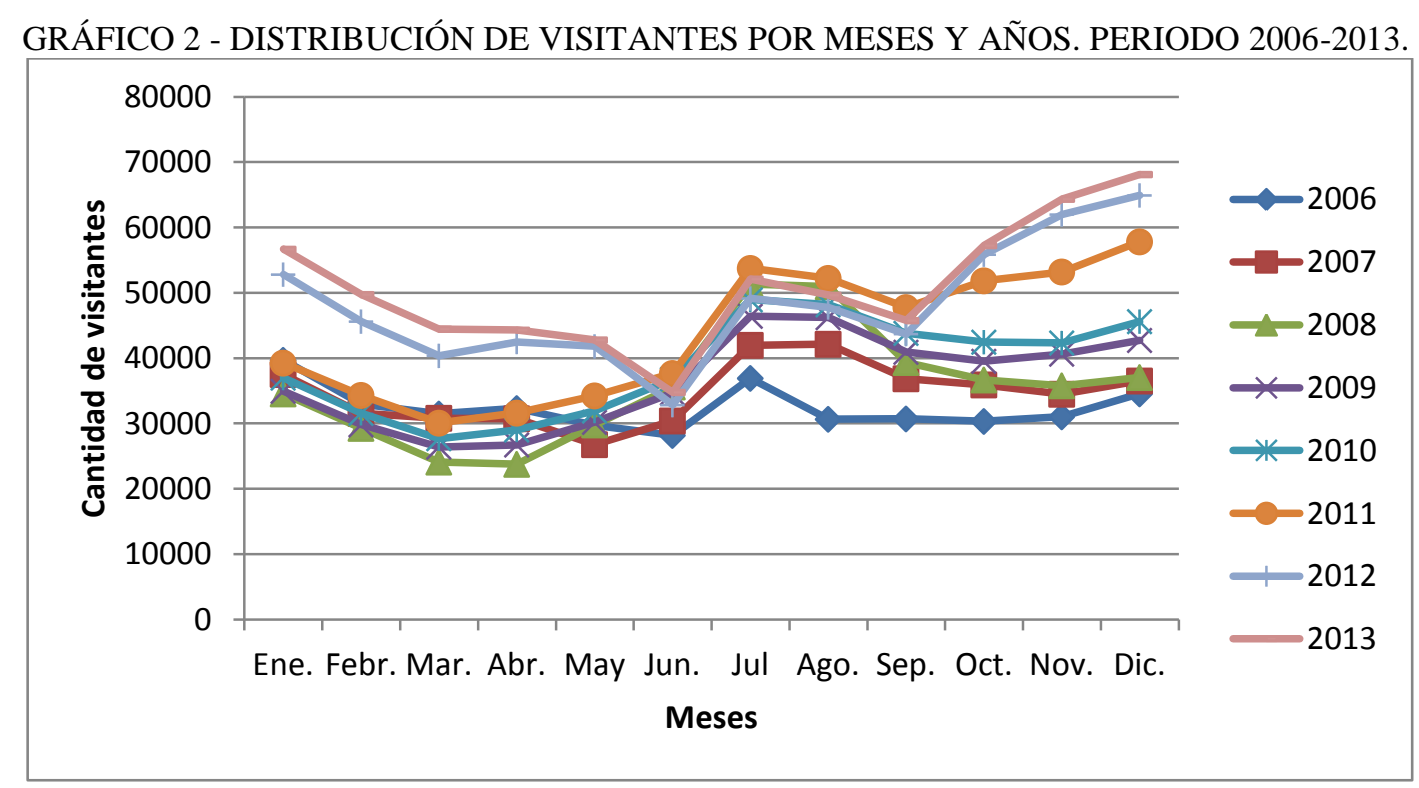

FUENTE: Elaboración propia datos de SENATUR y Dirección de Migraciones (2016).

De acuerdo a datos correspondientes al periodo 2010-2017, se observa que el $88,16 \%$ de los turistas provienen de los países del MERCOSUR, especialmente Argentina y Brasil. Es tal el predominio de los turistas de estas nacionalidades, que aproximadamente tres de cada cuatro que ingresan al país, son argentinos o brasileños (TABLA 2).

TABLA 2 - NACIONALIDAD DE LOS TURISTAS QUE LLEGAN AL PARAGUAY. PERIODO 2010 $-2017$

\begin{tabular}{|c|c|c|c|c|c|c|c|c|c|}
\hline \multirow{2}{*}{ País/Año } & \multicolumn{8}{|c|}{ Año } & \multirow{2}{*}{$\begin{array}{c}\text { Totales } \\
\text { por } \\
\text { países }\end{array}$} \\
\hline & 2010 & 2011 & 2012 & 2013 & 2014 & 2015 & 2016 & 2017 & \\
\hline Argentina & 218,418 & 222,901 & 254,328 & 271,897 & 308,367 & 848,387 & 932,373 & $1,189,074$ & $4,245,745$ \\
\hline Brasil & 159,280 & 176,440 & 171,925 & 191,451 & 183,127 & 190,003 & 202,946 & 229,352 & $1,504,524$ \\
\hline
\end{tabular}

\footnotetext{
${ }^{3}$ Se consideró este periodo debido a la información disponible en cuanto a la distribución mensual de los turistas y excursionistas que llegaron al Paraguay.
} 


\begin{tabular}{|l|r|r|r|r|r|r|r|r|r|}
\hline Otros paises & 13,309 & 19,102 & 28,152 & 26,144 & 31,662 & 31,630 & 31,653 & 27,051 & 208,703 \\
\hline Uruguay & 11,216 & 14,154 & 15,448 & 12,801 & 14,606 & 18,896 & 20,747 & 20,916 & 128,784 \\
\hline EE.UU & 10,142 & 11,285 & 17,280 & 18,677 & 19,204 & 19,479 & 16,840 & 15,424 & 128,331 \\
\hline Bolivia & 11,646 & 23,256 & 18,202 & 18,674 & 14,322 & 15,911 & 11,011 & 15,175 & 128,197 \\
\hline Chile & 9,829 & 11,706 & 11,780 & 11,042 & 14,403 & 17,946 & 18,010 & 14,758 & 109,474 \\
\hline España & 4,929 & 8,364 & 11,800 & 12,070 & 11,740 & 15,582 & 17,292 & 14,405 & 96,182 \\
\hline Alemania & 7,173 & 9,057 & 11,486 & 10,105 & 9,862 & 9,636 & 6,591 & 8,873 & 72,783 \\
\hline Colombia & 2,482 & 4,177 & 7,129 & 7,279 & 9,986 & 10,419 & 12,035 & 13,407 & 66,914 \\
\hline $\begin{array}{l}\text { Totales por } \\
\text { año }\end{array}$ & 448,424 & 500,442 & 547,530 & 580,140 & 617,279 & $1,177,889$ & $1,269,498$ & $1,548,435$ & \\
\hline
\end{tabular}

FUENTE: Elaboración propia a partir de datos de DGEEC y SENATUR (2018).

A partir de los datos señalados, es posible observar que el turismo receptivo aún tiene un desarrollo incipiente y que políticas públicas acordes, podrían favorecer a su desarrollo y diversificación. En las próximas líneas se considerarán aspectos económicos vinculados a esta actividad.

\section{INDICADORES ECONÓMICOS DEL TURISMO RECEPTIVO EN PARAGUAY}

El aporte del turismo receptivo a la economía del Paraguay puede ser medido con diversas variables. En primera instancia, se calculó el ingreso por visitantes para el periodo 2003-2017, para lo cual se consideró que el promedio de gasto de un turista es de USD 351 y el de un excursionista es de USD 20, estas cifras se desprenden de una estimación realizada por el BCP y la cual es utilizada por la SENATUR para evaluaciones en cuanto a la repercusión de este sector en la economía paraguaya.

De acuerdo al análisis efectuado para esta investigación, pudo establecerse que durante el periodo considerado, la actividad turística generó más de USD 4.160 millones de dólares, una cifra muy interesante para una economía pequeña como la paraguaya. El Gráfico 3 permite también, apreciar que el ingreso generado fue creciendo a través del tiempo y que el mismo superó los USD 619 millones en el año 2017. 
GRÁFICO 3 - INGRESO POR TURISMO RECEPTIVO EN PARAGUAY (USD). PERIODO 2003 2017

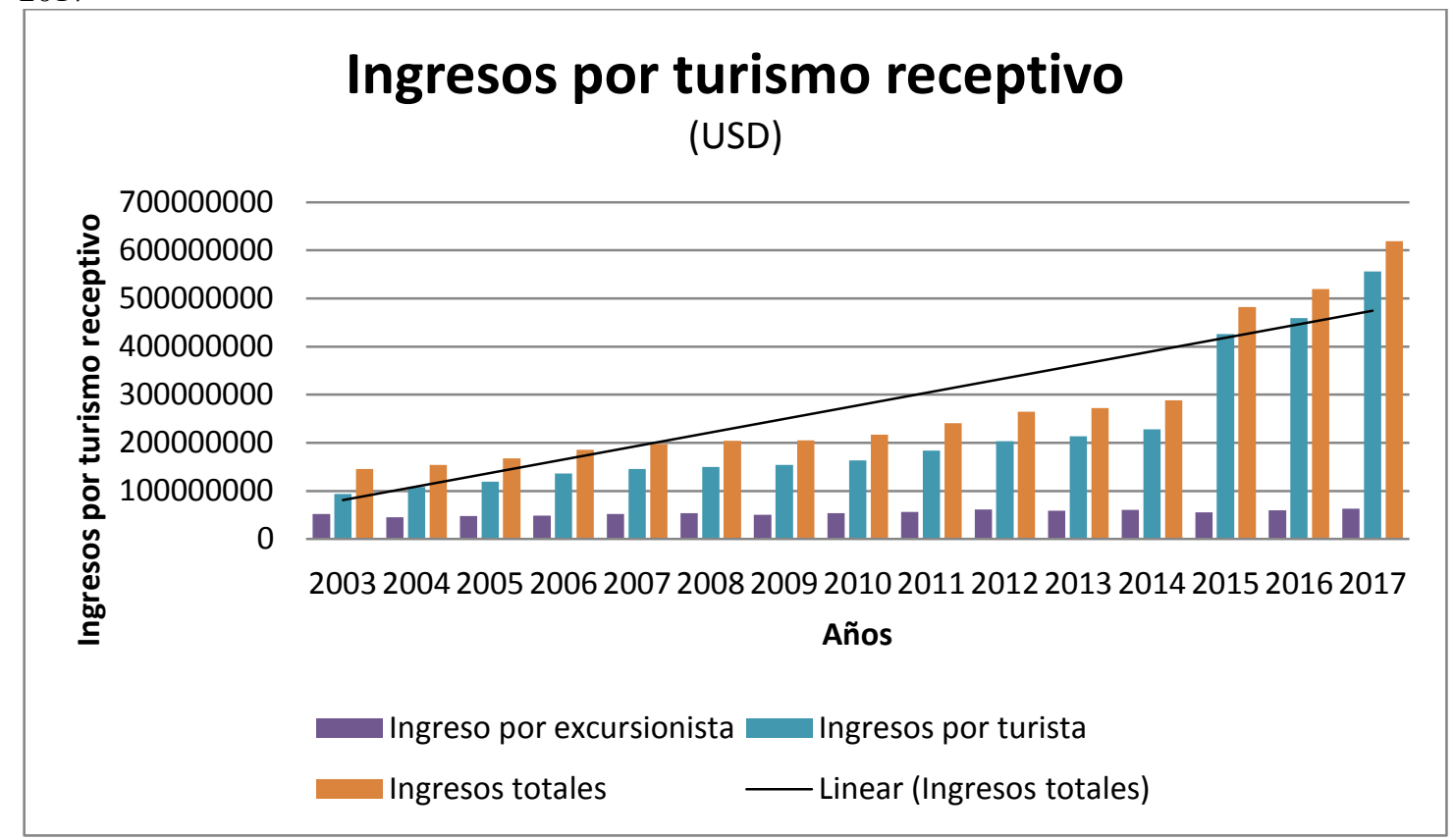

FUENTE: Elaboración propia a partir de datos proporcionados por SENATUR y BCP (2016, 2018).

Para comprobar el grado de relación que tienen los ingresos de turistas y el PIB, se analizó la relación entre las variables. Si bien es cierto que existe al respecto una amplia literatura y diversos modelos econométricos, se encontraron limitaciones en cuanto a los datos disponibles, por lo que se recurrió a una comparación de la evolución de ambas variables. Esto permitió apreciar que existe una relación positiva entre ambas variables, conforme se observa en el Gráfico 4.

GRÁFICO 4 - RELACIÓN ENTRE EL PIB Y EL INGRESO POR TURISMO EN PARAGUAY. PERIODO 2003 - 2017

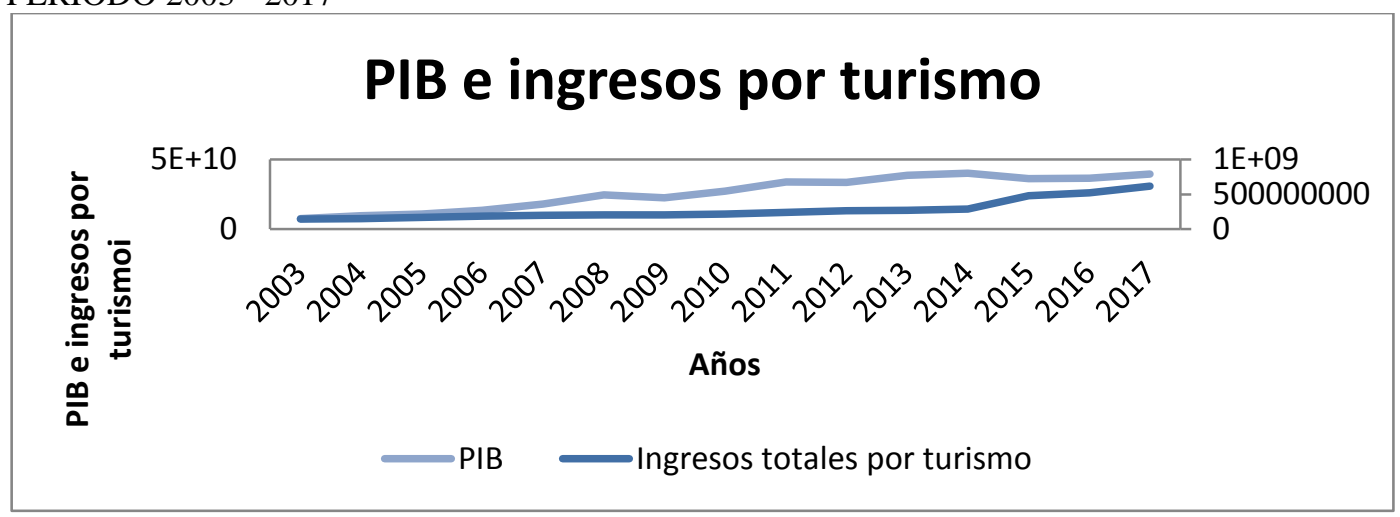

FUENTE: Elaboración propia de datos obtenidos de SENATUR y BCP $(2016,2018)$. 
Otro indicador que permite apreciar los efectos del turismo en la economía es el Gasto turístico receptor con respecto al PIB, indicador cuyo cálculo fue detallado en el apartado correspondiente a la metodología. El mismo permite apreciar la importancia relativa del turismo receptor en el PIB del país, el cual representa, en sentido amplio, a su economía (CEPAL, 2006). Su interpretación se realiza a partir de la siguiente premisa: a mayor valor de este índice, mayor es la relevancia del turismo receptivo en la economía en cuestión.

La importancia de esta magnitud radica en que permite apreciar la corriente monetaria asociada al turismo y puede permitir la comparación entre distintos países. Su evolución depende de distintos factores y es de utilidad para agentes públicos y privados.

El Gráfico 5 permite apreciar que la incidencia del turismo receptor en la economía paraguaya es variable y moderada. No obstante cabe resaltar la limitación del mismo, ya que fue construido a partir de un cálculo simplificado en el que se consideró solamente el gasto referencial del BCP y el total de visitantes, ante la inexistencia de otros insumos. Sería conveniente repetir el cálculo a partir de datos obtenidos de encuestas específicas que permitan el contraste entre los indicadores calculados.

GRÁFICO 5 - GASTO TURÍSTICO RECEPTOR RESPECTO AL PIB EN PARAGUAY. PERIODO $2003-2013$

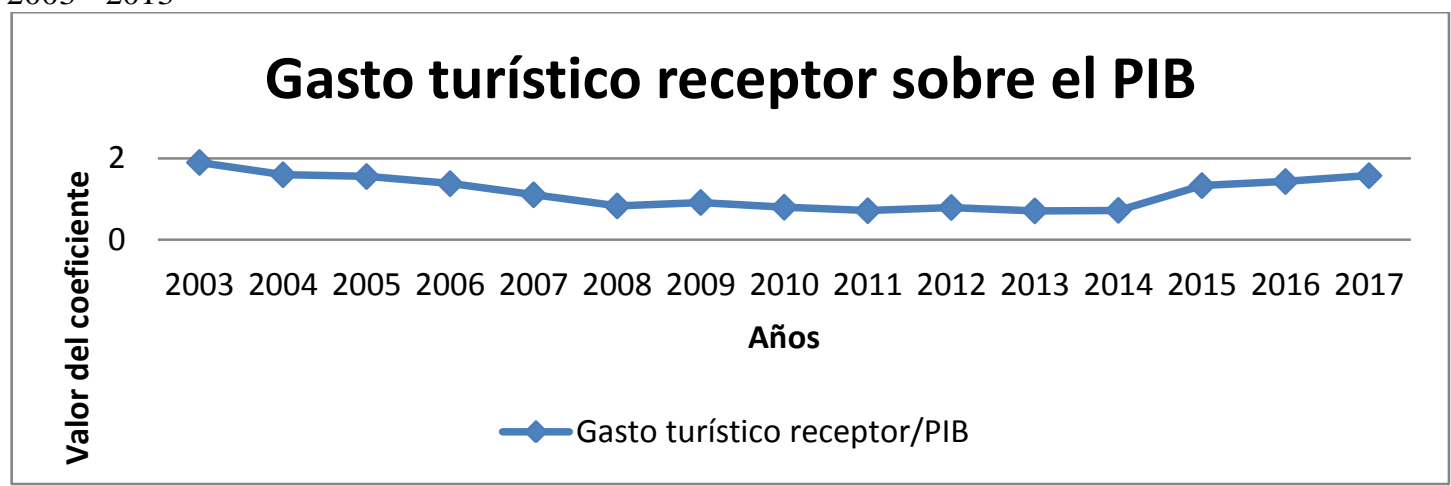

FUENTE: Elaboración propia a partir datos obtenidos SENATUR, CEPAL $(2016,2018)$.

Otro indicador de relevancia es el porcentaje de gasto turístico sobre las exportaciones totales del país. El mismo permite apreciar la importancia del turismo para las ventas internacionales del país, por lo que a mayor magnitud, mayor es la "vocación turística" del país. Su cálculo es importante porque permite tener una 
herramienta adicional que refleje el grado de especialización turística de un país y con ello poder tomar mejores decisiones (CEPAL; OMT, 2007).

GRÁFICO 6 - GASTOS DE TURISMO RECEPTIVO SOBRE EXPORTACIONES. PERIODO $2003-2013$

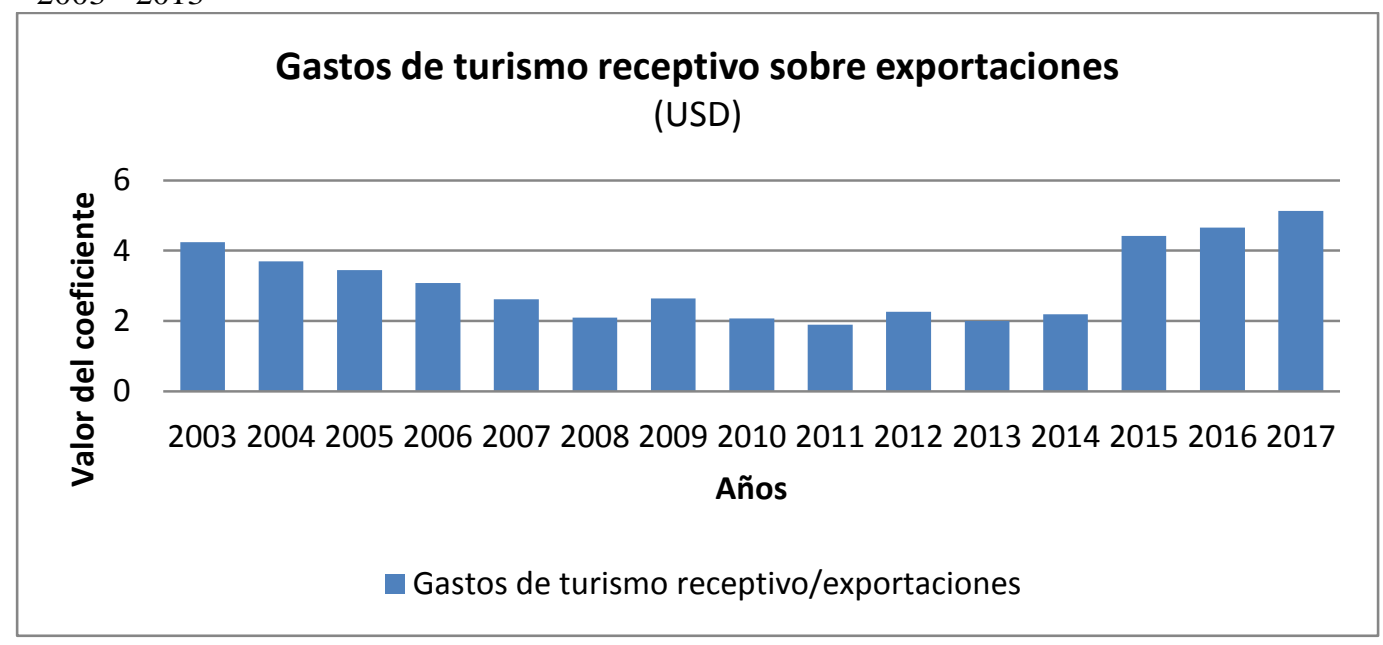

FUENTE: Elaboración propia a partir de datos obtenidos del Banco Mundial $(2016,2018)$.

El Gráfico 6, en el que se observa que su importancia relativa va disminuyendo hasta 2014 y brinda un salto en 2015, lo que resulta lógico si se considera que el turismo en ese año experimentó un aumento del $82 \%$. Al mismo tiempo, cabe resaltar que en el intervalo comprendido entre 2014-2017 las exportaciones fueron más bajas que las apreciadas en el periodo 2003 y 2013, lo que también influye en el aumento de la cuantía de este indicador.

\section{CONCLUSIONES}

El turismo es una actividad multidimensional, que tiene efectos para la economía, las sociedades y el territorio. La magnitud de estos efectos, sus beneficios o perjuicios, requiere de un análisis pormenorizado que implique las distintas aristas del tema para apreciar si la actividad es deseable o no.

De manera a contribuir con esto, la presente investigación abordó la contribución del turismo receptivo a la economía paraguaya durante el periodo 20032017. El primer dato que se desprende de la temática se vincula con la magnitud del turismo en el país, el cual totaliza más de 50.500.000 turistas y excursionistas durante 
los años observados. Si bien esta cifra es muy interesante, el turismo receptivo se encuentra aún en una fase incipiente en el Paraguay, pero ha crecido de forma sostenida, lo se debió a un esfuerzo conjunto entre el sector público y el sector privado.

También pudo notarse que el turismo receptivo ha mantenido cierta estacionalidad en el tiempo, posicionando a diciembre, julio, agosto y noviembre como los meses con mayor afluencia registrada. Adicionalmente, se detectó que las nacionalidades con mayor presencia entre los turistas que llegan al país son la de los países limítrofes, Argentina y Brasil, los que representan en promedio, el 85,93\% de los visitantes.

Pudo apreciarse también que la relación entre el PIB y los ingresos por turismo es positiva, según análisis gráficos. Sin embargo, cabe destacar que debido a la falta de datos más acabados en la materia, fue imposible implementar los modelos más sofisticados existentes en la literatura de la materia.

El ratio de gasto turístico receptor sobre el PIB permitió apreciar que la incidencia del turismo receptor es variable y moderada. La misma fue calculada a partir de los datos existentes, por lo cual se recomienda una generación de datos de mayor calidad y con este insumo recalcular los mismos.

El otro índice calculado es la incidencia de los gastos de turismo receptivo sobre exportaciones. El mismo tuvo un comportamiento oscilante en el periodo de estudio, aunque registró un marcado aumento entre 2015 y 2017. Este aumento en el ratio se dio, entre otras razones, por la disminución en la cuantía de las exportaciones totales del país.

Para coadyuvar a que el turismo siga creciendo, deben ser implementadas un conjunto de medidas además de las ya promovidas. La primera de ellas es el conocimiento preciso del sector, razón por la cual se recomienda incrementar los datos y estudios disponibles en la materia, lo que permitirá que se pueda analizar con mayor profundidad la temática.

\section{BIBLIOGRAFÍA}

ALTAMIRA VEGA, R.; MUÑOZ VIVAS, X. El turismo como motor de crecimiento Económico. Anuario Jurídico y Económico Escurialense, v. XL, 2007, p. 677 - 710. 
BANCO CENTRAL DEL PARAGUAY. Anexo Estadístico del Informe Económico. Asunción, Paraguay. Asunción, 2018. Disponible en: <https://www.bcp.gov.py/anexoestadistico-del-informe-economico-i365>. Accedido en: 11/06/2018.

COMISIÓN ECONÓMICA PARA AMÉRICA LATINA Y EL CARIBE (CEPAL). Indicadores Económicos del Turismo. Santiago, 2006. Disponible en: <https://repositorio.cepal.org/bitstream/handle/11362/4312/7/S2006061_es.pdf $>$. Accedido en: 04/06/2018.

CONGRESO DE LA NACIÓN PARAGUAYA. Ley N¹388 “Que crea la Secretaría Nacional de Turismo". Disponible en:

<http://www.sicpy.gov.py/gfx/download.php?502>. Accedido el: 11/06/2018.

DE LIMA MORAIS, I.; MARQUES ACIOLY, M. Pra lá do mundo existe um mundo comum: um estudo sobre relações entre turistas e moradores do Vale do Capão (Bahia/Brasil). Turismo e Sociedade. Curitiba, janeiro-abril v. 11, n. 1, 2018, p. 1-21.

DE RUS, G.; LEÓN, C. Economía del Turismo: Un Panorama. Revista de Economía Aplicada, v. 5, n. 15, 1997, p. 71-109.

ESTEBAN TALAYA, Á.; REINARES LARA, E. La investigación de la demanda turística en España: recopilación y análisis. Estudios Turísticos, n. 126, 1996, p. 81104.

FERREIRA LOPES, S. D.; VELOSO DA SILVA, J. A. Análisis estratégico de la oferta turística portuguesa. El análisis de importancia-valoración (IPA). Estudios y Perspectivas en Turismo, n. 20, 2011, p. 997-1008.

GRUPO DE INVESTIGACIÓN EN ECONOMÍA REGIONAL. Estudio de la demanda y oferta turística de la ciudad de Cuenca en el año 2016. Cuenca, 2017. Disponible en:

<http://cuenca.com.ec/sites/default/files/01\%20Informe\%20final\%20Estad\%C3\%ADsti cas\%202016.pdf >. Accedido el: 10/06/2018.

HERNÁNDEZ MARTÍN, R. Impacto Económico del Turismo. El Papel de las Importaciones como Fugas del Modelo. Información Comercial Española, ICE: Revista de economía, n. 817, 2004, p. 23-34.

MESA LONDOÑO, J. C.; ARANGO QUINTERO, J. C.; PULGARIN, M. I.; GÓMEZ PAZ, P. Caracterización de la oferta turística de Medellín y las subsedes de los IX Juegos Suramericanos 2010. Medellín: Esumer, 2010. Disponible en: <https://www.esumer.edu.co/images/centroeditorial/Libros/cip/libros/OFERTATURIST ICA.pdf> . Accedido el: 12/06/2018.

ORGANIZACIÓN MUNDIAL DE TURISMO. Entender el turismo: glosario básico. Disponible en: <http://media.unwto.org/es/content/entender-el-turismo-glosariobasico $>$. Accedido el: 05/06/2017. 
Panorama OMT del turismo internacional. Disponible en: $<$ https://www.eunwto.org/doi/pdf/10.18111/9789284419890>. Accedido el: 12/12/2018.

QUINTERO SANTOS, J. L. Los impactos económicos, socioculturales y medioambientales del turismo y sus vínculos con el turismo sostenible. Anales del Museo de América, v. 12, 2004, p. 263-274.

RODRIGUES MARINS, S.; FEDER MAYER, V.; FRATUCCI, A. Impactos percibidos del Turismo: un estudio comparativo con residentes y trabajadores del sector en Río de Janeiro - Brasil. Estudios y Perspectivas en Turismo, v. 24, 2015, p. 115134.

SAMUELSON, P.; NORDHAUS, W. Economía. 18. Ed. Madrid: Mc. Graw Hill Interamericana, 2006.

SANCHO, A. Introducción al Turismo. Organización Mundial del Turismo, 2008. Disponible en:

$<\underline{\text { http://moodle2.unid.edu.mx/dts_cursos_mdl/lic/AET/PT/AM/01/Introduccion_turismo }}$ .pdf>. Accedido el: 11/04/2018.

SECRETARÍA NACIONAL DE TURISMO DEL PARAGUAY (SENATUR). Plan Maestro de Turismo Paraguay. Asunción, 2012. Disponible en: <https://www.senatur.gov.py/application/files/9314/7920/7840/Plan_Maestro_de_Turis mo_-_Paraguay_2012-min.pdf >. Accedido el: 08/05/2018.

Estadísticas. Asunción, 2016 Disponible en:

$<$ http://www.senatur.gov.py/index.php?option=com_content $\&$ view=article \&id=33\&Ite mid=455>. Accedido el: 10/10/2016.

. Estadísticas. Asunción, 2018 Disponible en:

<http://www.observatur.gov.py/index.php/index/estadistica $>$. Accedido el: 11/06/2018.

Recebido em: 07-09-2018.

Aprovado em: 07-10-2018.

Versão finalizada para publicação em: 16-03-2019. 